\title{
Oxidative Degradation of Biorefinery Lignin Obtained after Pretreatment of Forest Residues of Douglas Fir
}

\author{
Keerthi Srinivas ${ }^{\mathrm{a}}$, Fernanda de Carvalho Oliveira ${ }^{\mathrm{b}}$, Philip Teller ${ }^{\mathrm{a}}$, Adilson Roberto Goncalves ${ }^{\mathrm{b}}$, \\ Greg Helms ${ }^{\mathrm{c}}$ and Birgitte Kaer Ahring*a \\ ${ }^{a}$ Bioproducts, Sciences and Engineering Laboratory, Washington State University, Tri-Cities, Richland, WA-99354 \\ ${ }^{b}$ Biotechnology Department, Engineering School of Lorena, University of São Paulo,, Lorena-SP, Brazil-12.602- \\ 810 \\ ${ }^{c}$ Center for NMR Spectroscopy, Washington State University, Pullman, WA-99164
}

Biorefinery lignin stream obtained after wet explosion pretreatment of forest residues were further degraded using wet oxidation to produce high-value biochemicals. The biorefinery lignin stream was characterized to understand efficiency of oxidative degradation process.

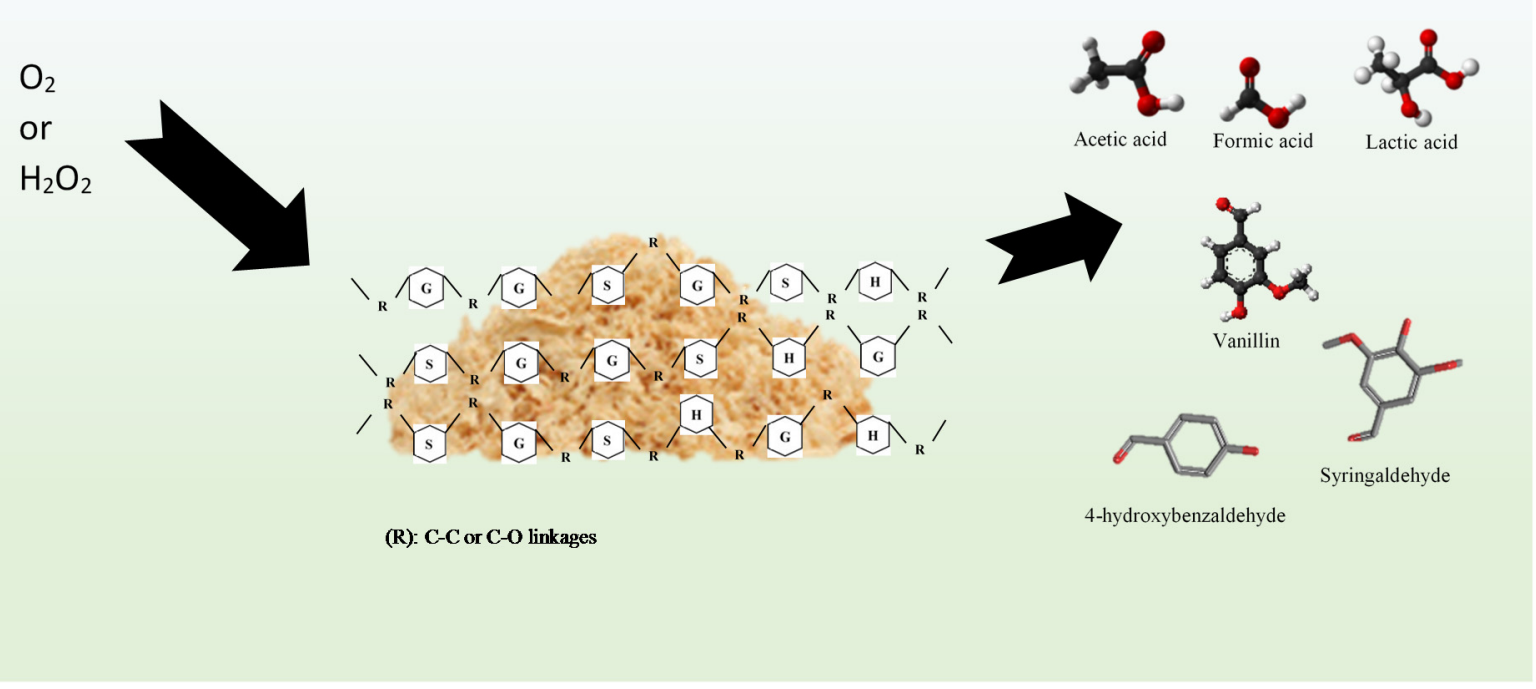

*Corresponding author

Dr. Birgitte Ahring

Bioproducts, Sciences and Engineering Laboratory

Washington State University, Tri-cities

2710 Crimson Way

Richland, WA 99354

Tel.: 01-(509)-372-7682

Fax: 01-(509)-372-7690.

E-mail address: bka@wsu.edu 


\title{
Oxidative Degradation of Biorefinery Lignin Obtained after Pretreatment of Forest Residues of Douglas Fir
}

\author{
Keerthi Srinivas $^{\mathrm{a}}$, Fernanda de Carvalho Oliveira ${ }^{\mathrm{b}}$, Philip Johan Teller ${ }^{\mathrm{a}}$, Adilson Roberto \\ Gonçalves $^{\mathrm{b}}$, Greg Helms ${ }^{\mathrm{c}}$ and Birgitte Kaer Ahring ${ }^{* a}$
${ }^{a}$ Bioproducts, Sciences and Engineering Laboratory, Washington State University, Tri-Cities, Richland, WA-99354
${ }^{b}$ Biotechnology Department, Engineering School of Lorena, University of São Paulo, Lorena-SP, Brazil-12.602-810 \\ ${ }^{c}$ Center for NMR Spectroscopy, Washington State University, Pullman, WA-99164
}

Abstract:

Harvested forest residues are usually considered a fire hazards and used as "hog-fuel" which results in air pollution. In this study, the biorefinery lignin stream obtained after wet explosion pretreatment and enzymatic hydrolysis of forestry residues of Douglas fir (FS-10) was characterized and further wet oxidized under alkaline conditions. The studies indicated that at $10 \%$ solids, $11.7 \mathrm{wt} \%$ alkali and $15 \mathrm{~min}$ residence time, maximum yields were obtained for glucose $(12.9 \mathrm{wt} \%)$, vanillin $(0.4 \mathrm{wt} \%)$ at $230^{\circ} \mathrm{C}$; formic acid $(11.6 \mathrm{wt} \%)$ at $250^{\circ} \mathrm{C}$; acetic acid $(10.7 \mathrm{wt} \%)$, hydroxybenzaldehyde $(0.2 \mathrm{wt} \%)$, syringaldehyde $(0.13 \mathrm{wt} \%)$ at $280^{\circ} \mathrm{C}$; and lactic acid $(12.4 \mathrm{wt} \%)$ at $300^{\circ} \mathrm{C}$. FTIR analysis of the solid residue after wet oxidation showed that the aromatic skeletal vibrations relating to lignin compounds increased with temperature indicating that higher severity could result in increased lignin oxidation products. The results obtained, as part of the study, is significant for understanding and optimizing processes for producing high-value bioproducts from forestry residues.

Keywords: Biochemical, Biorefinery, Douglas Fir, Lignin, Wet Oxidation.

\footnotetext{
* Corresponding author

Dr. Birgitte Ahring

Bioproducts, Sciences and Engineering Laboratory

Washington State University, Tri-cities

2710 Crimson Way

Richland, WA 99354

Tel.: 01-(509)-372-7682

Fax: 01-(509)-372-7690.

E-mail address: bka@wsu.edu
} 
22 One of the major problems affecting the forestry reserves in the Pacific Northwest region of the

23 United States is the high-intensity wildfires caused as the result of residuals left behind after

24 logging and harvesting of the forest. Removal of these residues is further of importance for

25 overall insect, pest and disease resistance in the forests (Jurgensen et al., 1997). Official report,

26 as of 2012, indicated an estimated amount of 75 million tons of harvest residues being produced

27 every year (Perlack and Stokes, 2011). Studies have also indicated that thinning activities to

28 avoid wild fires in the western United States alone can result in 155Mt of "waste" residual

29 lignocellulosic biomass (Rummer et al., 2005). These forest residual wastes can be, instead, used

30 as a low-cost raw material for the production of biofuels and biochemicals.

31 In biorefineries, the biomass will be ground and pretreated to break the acetate linkages between

32 lignin and hemicellulose followed by enzymatic action on the cellulosic components to yield

33 sugar monomers. These sugar monomers (eg. glucose/xylose) are then further fermented using

34 microbes to produce biofuels such as ethanol or butanol. Forest residues might be low in cost but

35 the high recalcitrance of the forest residuals usually results in a significant increase in the

36 production costs (Cheng et al., 2015, Stephen et al., 2010). The recalcitrance of these forestry

37 residues is due to the presence of recalcitrant wood materials that amounts to at least $15-25 \%$ of

38 the whole tree mass (David and Atarbouch, 1987). These studies have indicated that the presence

39 of bark material increases the amount of extractives, organic acids and lignin in the forestry

40 residues resulting in decreased saccharification efficiency primarily through inhibition of the

41 cellulolytic enzymatic activity. Recent studies have focused on the efficient pretreatment of these

42 forestry residues using sulfite pretreatment or SPORL (Zhu et al., 2015) and wet explosion 
43 pretreatment (Biswas et al., 2015). Both these pretreatments followed by enzymatic action

44 resulted in effective biomass degradation to produce high sugar yields.

45 The focus of the current study is on the biorefinery lignin stream obtained from these forestry 46 residues and its ability to be converted to high value bioproducts. Lignin is a highly branched

47 amorphous heteropolymer connected through a system of C-C and phenylpropane linkages and is

48 made up from oxidative coupling of hydroxyphenyl $(\mathrm{H})$, guaiacyl $(\mathrm{G})$ and syringyl (S)

49 components (Himmel et al., 2007). While the SPORL pretreatment of the forest residues results

50 in formation of lignosulfonates, studies have indicated that the lignin obtained from wet

51 explosion pretreatment retained its native structure with limited modifications primarily since

52 there were no harmful chemicals added during the pretreatment process (Rana et al., 2015).

53 Briefly, wet explosion pretreatment is a combination of wet oxidation and steam explosion using

54 oxygen as main oxidant to degrade lignocellulosic biomass structure (Biswas et al., 2015; Rana

55 et al., 2012). Previous studies on wet exploded loblolly pine lignin at optimal conditions for

56 sugar production indicated that structural modifications within the lignin molecule occurred in

57 the form of methoxylation of the hydroxyphenyl components present in lignin (Rana et al.,

58 2015). These studies indicated that an increase in the methoxylation of the lignin components

59 resulted in a reduced recondensation and reploymerization of the lignin making it an ideal

60 feedstock for further conversions, which potentially could lead to bio-products of high value,

61 which could bring down the cost of biofuels production. Also in most studies on lignin, the

62 sugars are separated from the lignin fraction using either alkali treatment (Rocha et al., 2012) or

63 using organic solvents (Rana et al., 2015; Ke et al., 2011) resulting in a cleaner lignin fraction for

64 further deconstruction to biochemicals. However, these purification/separation processes can 
65 significantly affect process economics and the absence of data on the structure of lignin from

66 forestry residues further complicates process design.

67 The aim of this study is to characterize the lignin stream obtained from a cellulosic biorefinery

68 using Douglas fir forestry residues as feedstocks and evaluate potential oxidative degradation

69 compounds that can be formed from the lignin side-stream residing after sugar removal. In this

70 process, the biorefinery lignin stream is obtained after wet explosion pretreatment followed by

71 enzymatic hydrolysis of the biomass. The lignin stream is washed to remove solubilised

72 components, such as residual sugars and some extractives, and no further purification is

73 performed, indicating that residual cellulose, some organic acids and some salt will also be

74 present apart from lignin. In order to demonstrate the types of biochemicals that can be released,

75 we used more extreme wet oxidation under alkaline conditions, high temperatures and low

76 residence time. The residue left behind after wet oxidation of biorefinery lignin was also

77 characterized using spectrophotometric techniques to evaluate the extent of oxidative

78 degradation.

\section{Materials and Methods}

$80 \quad 2.1$ Chemicals

81 Reagent grade $35 \mathrm{wt} \%$ hydrogen peroxide in water, ethyl acetate (HPLC grade), $95 \mathrm{wt} \%$ sulfuric

82 acid in water, $50 \mathrm{wt} \%$ sodium hydroxide in water, $1 \mathrm{~N}$ hydrochloric acid concentrate and

83 analytical standards for glucose, xylose, acetic acid, lactic acid, formic acid, vanillin,

84 syringaldehyde, hydroxybenzaldehyde, cellobiose, furfural and hydroxymethyl furfural was

85 obtained from Sigma Aldrich (St. Louis, MO, USA). Cellulase (Cellic Ctec2) and hemicellulase

86 (Cellic Htec2) was obtained from Novozymes Inc. (Franklinton, NC, USA). 


\subsection{Feedstock and Composition}

88 The Douglas Fir FS-10 sample used in the study is similar to that has been used previously

89 (Biswas et al., 2015). The FS-10 sample was obtained from Weyerhauser

90 (www.weyerhauser.com, Federal Way, WA, USA) and was mainly composed of Douglas Fir

91 (64\%), Hemlock (15\%), Cedar (1\%), Pine (1\%), Spruce (3\%), Balsam fir (1\%) and Maple

92 Hardwood (15\%) residues (by weight basis). The dry biomass sample was milled using a Retsch

93 cutting mill SM 200 (Retsch Inc. Newtown, PA, USA), screened and sieved through a $1.6 \mathrm{~mm}$

94 mesh. The FS-10 sample was then wet exploded according to the method previously described

95 (Biswas et al., 2015; Rana et al., 2015), using a temperature of $185^{\circ} \mathrm{C}, 25$ min residence time and

$965 \% \mathrm{O}_{2}$ loading, followed by enzymatic hydrolysis using $40 \mathrm{mg}$ enzyme $/ \mathrm{g}$ cellulose with a 90/10

97 Ctec2/Htec2 (Novozyme) enzyme mixture. These conditions were selected based on preliminary

98 experiments intended for maximum lignocellulosic biomass deconstruction with minimal effect

99 on the lignin structure (Biswas et al., 2015). The wet explosion pretreatment of FS-10 was done

100 under non-alkaline conditions with a measured reaction $\mathrm{pH}$ between 5 and 6 . The hydrolysate is

101 filtered and the solids left behind was washed with 3 bed volumes of water and dried in a

102 convection oven at $40^{\circ} \mathrm{C}$ overnight. The dried solids were then powdered using a benchtop ball

103 mill (3 lbs capacity; www.pyrocreations.com) for 8 hours and used as "biorefinery lignin" feed

104 for further experiments. The carbohydrate, lignin and extractive compositional analysis of the

105 dried and milled biorefinery lignin (moisture content $<2 \%$ ) and that of original FS-10 sample

106 before pretreatment was done using Laboratory Analytical Procedures (LAPs) from National

107 Renewable Energy Laboratory (Sluiter et al., 2011).

108

\subsection{Alkaline Wet Oxidation}


Alkaline wet oxidation of biorefinery lignin was carried out in $15 \mathrm{~mL}$ stainless steel tubes (6" length x 0.5 " i.d, Swagelok, WA, USA). The biorefinery lignin (dried and milled) was mixed with a hydrogen peroxide solution in stainless steel tubes and placed in a preheated fluidized sand bath (Techne Model SBL-2D, VWR International, Batavia, IL, USA) controlled using Eurotherm TC-8D controller. The final volume in the tubes was maintained at $10.5 \mathrm{~mL}$ to allow sufficient headspace during the oxidations. Initial experiments were performed without addition of alkali and process conditions tested include $10 \%$ solids loading, temperatures from 180 to $300^{\circ} \mathrm{C}$ and 5 and 15 min residence times. Based on these preliminary tests (data not included), 1 min preheat time was allotted for stainless tubes to reach temperatures below $250^{\circ} \mathrm{C}$ and $1.5 \mathrm{~min}$ preheat time was used for temperatures between 250 and $300^{\circ} \mathrm{C}$. The residence times used in experimental design does not include this preheat time. Second set of experiments was performed through addition of alkali at $1 \mathrm{~g} / \mathrm{g}$ dry biorefinery lignin (11.7 wt $\%$ alkali) and $1.5 \mathrm{~g} / \mathrm{g}$ dry biorefinery lignin (17.4 wt\% alkali) at the similar experimental (temperature and residence time) conditions as specified previously. After wet oxidation, the stainless steel tubes were placed in an ice-water bath until the tubes were cooled to below room temperature. The wet oxidized samples from the reaction tubes were then transferred to centrifuge tubes and the reaction tubes were washed with known volume of water. The wash water was added to the centrifuge tubes and mixed before centrifuging at 10,000 rpm for $5 \mathrm{~min}$ to separate out the solids from the liquid. In case of alkaline wet oxidation, the samples were neutralized with hydrochloric acid (1N) before centrifugation. The liquid samples were appropriately diluted and analyzed using HPLC while the solids were analyzed using FTIR. All experiments were run in duplicate and the standard error bars are shown in the figures.

\subsection{Liquid Fraction Analysis}


132 The liquid samples were filtered through a $0.2 \mathrm{~mm} 45$-micron syringe filters and run through a

133 Dionex Ultimate 3000 (Sunnyvale, CA, USA) high performance liquid chromatography (HPLC)

134 system equipped with Aminex 87H column 250 X $4.6 \mathrm{~mm}$ (Biorad, CA, USA) using the

135 following conditions: eluent (4mM sulfuric acid in water) flowing through column (maintained 136 at $60^{\circ} \mathrm{C}$ ) at $0.6 \mathrm{~mL} / \mathrm{min}$ for 120 minutes.

137 The samples were further analyzed using gas chromatograph fitted with a mass spectrometer 138 (GC-MS) to determine the amount of lignin-based phenolic compounds produced during wet 139 oxidation. $4 \mathrm{~mL}$ of ethyl acetate was added to $2 \mathrm{~mL}$ of sample and placed in an ultrasonic water 140 bath (Bransonics 3510R-DTH, CT, USA) preheated to $65^{\circ} \mathrm{C}$ and sonicated for $1 \mathrm{~h}$ at $40 \mathrm{kHz}$.

141 During this process, all the lignin-derived organic compounds will be selectively extracted into 142 the ethyl acetate phase and can be recovered by properly pipetting out the supernatant after 143 cooling to room temperature conditions. The GC-MS conditions for analysis were similar to 144 described in previous work (Rana et al., 2015). Briefly, $1 \mu \mathrm{L}$ sample was injected into helium 145 (used as carrier gas) flowing at $60 \mathrm{~mL} / \mathrm{min}$ which then passes through a DB-5 (30m length $\mathrm{X}$ $146250 \mu \mathrm{m}$ I.D. X $0.25 \mu \mathrm{m}$ thickness, J\&W Scientific, Folsom, CA, USA) capillary column fitted in 147 an Agilent 7890A GC (Santa Clara, CA, USA). The eluting compounds were detected using an 148 Agilent 5975C inert XL EI/CI mass spectrometer with triple axis and characterized using 149 existing NIST libraries. The GC conditions using split-less injection to separate the compounds 150 were: $100^{\circ} \mathrm{C}$ for $5 \mathrm{~min} ; 270^{\circ} \mathrm{C}$ at $5^{\circ} \mathrm{C} / \mathrm{min}$, hold for $5 \mathrm{~min}$ with a total run time of $44 \mathrm{~min}$. The 151 injector was maintained at $300^{\circ} \mathrm{C}$. The MS conditions for analysis were 5 min solvent delay, $152230^{\circ} \mathrm{C}$ source temperature, $150^{\circ} \mathrm{C}$ quad temperature, mass fragments collected between 25 and 1531000 a.m.u. and gain factor of 1 . The lignin-based components present in the liquid samples 154 were characterized using the GC-MS and expressed in terms of \% peak area as follows: 


$$
\% \text { Area }=\frac{\text { Sum of peak areas of } G / H / S \text { type compounds from } G C-M S}{\text { Sum of all peak areas of } G, H \& S \text { compounds from } G C-M S} \times 100
$$

156

157

158

159

160

161

162

163

164

165

166

167

168

169

170

171

172

173

174

175

\subsection{Solid Fraction Analysis}

\subsubsection{Solid-State Nuclear Magnetic Resonance (NMR) Spectrometry}

Solid-state NMR data for the biorefinery lignin was collected on an Agilent DD2 $600 \mathrm{MHz}$ console (Agilent, CA, USA) with an Agilent $4 \mathrm{~mm}$ double-resonance probe. The spectrometer frequency for collection of $\mathrm{C}^{13}$ was $150.808 \mathrm{MHz}$. The data were collected with $\mathrm{CP}-\mathrm{MAS}$ with and without TOSS-4 for suppression of the sidebands. The spinning rate was $6 \mathrm{KHz}$, the initial ${ }^{1} \mathrm{H} 90$ degree pulse was $2.2 \mu \mathrm{s}$ and the cross polarization contact time was $1 \mathrm{~ms}$ using a $50 \%$ linear ramped ${ }^{1} \mathrm{H}$ spin lock. ${ }^{1} \mathrm{H}$ decoupling was accomplished with SPINAL-64 modulation at a decoupling field of $94 \mathrm{KHz}$. The acquisition time was $20 \mathrm{~ms}$ and 1024 scans were acquired per sample with a relaxation delay of 5 seconds. TOSS-4 was used for suppression of sidebands and was optimized using a sample of glycine spinning at $6 \mathrm{KHz}$ and chemical shifts were referenced using the glycine carboxyl carbon at $173.03 \mathrm{ppm}$. Data were anodized with $20 \mathrm{~Hz}$ of exponential line broadening, zero filled to 4096 points and Fourier Transformed.

The resonances were broadly assigned as follows: $\mathrm{CH}_{3}$ in acetyl groups of hemicellulose (21-24 ppm), alkyl $\mathrm{CH}$ and $\mathrm{CH}_{2}$ in lignin subunits (30-40 ppm), methoxy groups in lignin $\mathrm{G}$ and $\mathrm{S}$ units (56 ppm), $\mathrm{C}_{6}$ carbon atoms in carbohydrates (63 ppm), $\mathrm{C}_{2}, \mathrm{C}_{3}$ and $\mathrm{C}_{5}$ carbon atoms in carbohydrates ( $73 \mathrm{ppm})$, sugars in hemicellulose (82 ppm), $\mathrm{C}_{4}$ carbon atoms in carbohydrates (89 ppm), $\mathrm{C}_{1}$ carbon atoms in carbohydrates $(105 \mathrm{ppm})$, unsubstituted olefinic or aromatic carbon atoms (110-127 ppm), quaternary olefinic or aromatic carbon atoms (127-143 ppm), olefinic or 
176 aromatic carbon atoms with $\mathrm{OH}$ or RO substituents (143-167 ppm), esters and carboxylic acids

177 (169-195 ppm) at 173 ppm, carbonyl groups in lignin (195-225 ppm) (Capanema et al, 2005).

178

179

180

181

182

183

184

185

186

187

188

189

190

191

192

193

194

195

196

197

\subsubsection{Fourier Transform Infrared (FTIR) Spectroscopy}

For analysis in the infrared region, samples containing $1 \mathrm{mg}$ of either the biorefinery lignin or residual solids after wet oxidation were dried for $24 \mathrm{~h}$ in a constant temperature oven and placed in a desiccator. The sample was then mixed with $250 \mathrm{mg}$ of potassium bromide $(\mathrm{KBr})$ and processed into tablets by compression and subjected to analysis in the infrared region (400-4000 $\mathrm{cm}^{-1}$ ) using Perkin Elmer Spectrum GX (Waltham, MA, USA). The lignin spectra were normalized using spectral data at band $1510-1513 \mathrm{~cm}^{-1}$, corresponding to aromatic ring vibrations (Faix et al., 1994). The assignment of FTIR bands are shown in Table S1 (Kubo and Kadla, 2005; Pandey, 1999).

\section{Results and Discussion}

\subsection{Compositional Analysis and Characterization of Biorefinery Lignin}

The sugar and lignin composition of the original FS-10 and the biorefinery lignin (after wet explosion and enzymatic hydrolysis of FS-10) are shown in Table 1. It can be seen from Table 1 that the biorefinery lignin still contained about $23 \mathrm{wt} \%$ cellulose while most of the hemicellulose was dissolved after wet explosion pretreatment.

Solid-state NMR spectra for the original FS-10 and biorefinery lignin is shown in Figure S1 and discussed in detail in the supplementary section of this manuscript. Due to the presence of sugar components in the biorefinery lignin, there was no specific trends observed between FS-10 and biorefinery lignin except for a significant reduction in the acetate methyl linkages in the biorefinery lignin after wet explosion. The NMR spectra also indicated a slight increase in the 
methoxy linkages associated with G- \& S- units of lignin at 56 ppm. Similar trends were previously observed with wet explosion pretreatment of loblolly pine and was postulated to be a result of in-situ methoxylation of the hydroxyphenyl- $(\mathrm{H}-)$ components during wet explosion 201 pretreatment (Rana et al., 2015).

202 Fourier Transform Infrared (FTIR) spectroscopy is commonly used for the characterization of 203 the functional groups of the lignocellulosic biomass and changes caused by different treatments 204 (Sim et al., 2012). While softwood contains predominantly only G- components, the FS-10 205 biomass contains both softwood and hardwood residues which results in the presence of some S206 components too. The biorefinery lignin obtained from wet explosion pretreatment of FS-10 was 207 found to have both softwood and hardwood properties and showed an uncharacteristic peak (not 208 usually seen in FTIR spectra of softwood such as Douglas Fir) (Dence and Lin, 1992) 209 representing $\mathrm{C}-\mathrm{O}$ stretching of syringyl group at $1318 \mathrm{~cm}^{-1}$. Previous studies have indicated that 210 the G-type lignin absorbs in both 1270 and $1230 \mathrm{~cm}^{-1}$ bands, S-type lignin components absorbed 211 mostly in the $1230 \mathrm{~cm}^{-1}$ bands (Pandey, 1999). The FTIR spectra of the biorefinery lignin is 212 shown in Figure S2 of the supplementary information section attached to this manuscript. The $213 \mathrm{~S} / \mathrm{G}$ ratio of the biorefinery lignin was found to be 0.88 by comparing the FTIR absorbance at $2141270 \mathrm{~cm}^{-1}$ and $1225 \mathrm{~cm}^{-1}$ respectively. The small peak shift for the syringyl units was caused due 215 to the mixed nature of biomass. Further trends observed in the FTIR spectra of biorefinery lignin 216 is discussed in detail in the supplementary section.

217 Based on the solid-state NMR and FTIR data, it can be hypothesized that further wet oxidation 218 of the biorefinery lignin obtained from FS-10 will result in production of greater quantities of 219 sugar oxidation products due to the higher percentage of cellulosic moieties still left behind. It 
can also be predicted that among the lignin oxidation products, G-type units will be significantly higher.

\subsection{Effect of temperature, residence time and alkali loading on yield of sugar oxidation products}

The yields of sugar oxidation and degradation products as a function of temperature, residence time and alkali loading at $10 \%$ solids is shown in Table 2 and the trends for glucose, lactic acid and formic acid along with the standard deviations are shown in Figure 1. While glucose and formic acid can be produced as a result of thermal degradation of cellulose, the primary oxidation product from cellulosic component in the biorefinery lignin would be lactic acid (and acetic acid which will be discussed separately). It can be seen from Figure 1 that wet oxidation under alkaline conditions resulted in greater yields for glucose, lactic acid and formic acid with maximum yields of $129 \pm 6.49 \mathrm{mg}$ glucose $/ \mathrm{g}$ dry biorefinery lignin at $230^{\circ} \mathrm{C} ; 116 \pm 1.71 \mathrm{mg}$ formic acid/g dry biorefinery lignin at $250^{\circ} \mathrm{C}$; and $124 \pm 0.01 \mathrm{mg}$ lactic acid/g dry biorefinery lignin at $300^{\circ} \mathrm{C}$ with an alkali loading of $1 \mathrm{~g} / \mathrm{g}$ biomass $(11.7 \mathrm{wt} \%$ alkali $)$ and residence time of $15 \mathrm{~min}$. Such trends have been previously observed especially for lactic acid where the lactic acid yield increased with an increase in temperature up to $300^{\circ} \mathrm{C}$ followed by a decrease due to significant thermal degradation (Jin et al., 2005). These studies had indicated maximum yields for lactic acid of around $100 \mathrm{mg} / \mathrm{g}$ dry feed from pure cellulose within two minutes of reaction at $300^{\circ} \mathrm{C}$ at an oxygen loading as high as $70 \%$. Compared to the literature that uses higher oxygen loading than $7.5 \%$ used in our experiments, the results showed slightly higher lactic acid yields at similar temperature but higher residence times. No significant difference in the yields of glucose, formic acid and lactic acid could be observed in Figure 1 as a function of alkali loading. Few anomalies to this conclusion can be seen at $250^{\circ} \mathrm{C}$ and $11.7 \mathrm{wt} \%$ alkali where there was a significant difference in the glucose and lactic acid yields at the different alkali loadings. However, this can 
243 be attributed to the thermal degradation of glucose and lactic acid as shown by an increase in the

244 formic acid yields at $250^{\circ} \mathrm{C}$. Previous study (Demesa et al., 2015) have shown significant

245 production of formic acid from oxidation of technical lignin but in the current study, formic acid

246 yields are commensurate with thermal degradation of glucose and hence, has been considered as

247 primarily being obtained from sugar components present in the biorefinery lignin.

248

249

250

251

252

253

254

255

256

257

258

259

260

261

262

263

264

265

\subsection{Effect of temperature, residence time and alkali loading on yield of lignin oxidation} products

The yields of lignin oxidation products (vanillin, syringaldehyde and hydroxybenzaldehyde) as a function of temperature, residence time and alkali loading at $10 \%$ solids are shown in Table 2 and Figure 2. As can be seen from Figure 2(a) (i) \& (ii), there was no significant effect of residence time and alkali loading on the vanillin yield from the alkaline wet oxidation of biorefinery lignin. The insignificant effect of alkali loading on vanillin yield above $\mathrm{pH}$ of 11.5 has been previously seen where a two-fold increase in alkali concentration above $1.2 \mathrm{~g} / \mathrm{g}$ lignin resulted only in a marginal increase in vanillin yields (Mathias and Rodrigues, 1995). There was, however, a significant effect of temperature with maximum yield of $3.85 \pm 0.24 \mathrm{mg}$ vanillin/g dry biorefinery lignin at $230^{\circ} \mathrm{C}, 11.7 \mathrm{wt} \%$ alkali loading and $15 \mathrm{~min}$ residence time. It was also seen that there was no significant difference between vanillin yields at 230 and $250^{\circ} \mathrm{C}$ and different residence times when alkali loading was $11.7 \mathrm{wt} \%$. However, there was a significant effect of residence time and temperature on the hydroxybenzaldehyde and syringaldehyde yields with maximum values of $2.01 \pm 0.02 \mathrm{mg} / \mathrm{g}$ dry biorefinery lignin and $1.32 \pm 0.02 \mathrm{mg} / \mathrm{g}$ dry biorefinery lignin respectively at $280^{\circ} \mathrm{C}, 11.7 \mathrm{wt} \%$ alkali loading and $15 \mathrm{~min}$ residence time. Since there is only around $56.8 \mathrm{wt} \%$ of lignin in the biorefinery lignin feed, the theoretical maximum yields of vanillin, syringaldehyde and hydroxybenzaldehyde was calculated as $6.79,2.32$ and $3.54 \mathrm{mg} / \mathrm{g}$ 
266 dry pure lignin respectively. While vanillin yields as high as $12 \mathrm{wt} \%$ has been shown from

267 softwood lignin (Fache et al., 2016), the recalcitrance of the biorefinery lignin from mixed

268 forestry residues should be taken into consideration along with the high temperatures tested in

269 the study, which could lead to a decrease in expected vanillin yields. Another reason for lower

270 yields of lignin oxidation products when compared to the afore-mentioned studies is that they has

271 used a lower solids loading $(\leq 6 \mathrm{wt} \%)$ when compared to the current study.

272 As can be seen from Figures 2(b) (ii) and (c) (ii), the hydroxybenzaldehyde and syringaldehyde

273 yields increased significantly above $250^{\circ} \mathrm{C}$ followed by a decrease at $300^{\circ} \mathrm{C}$ probably due to

274 thermal degradation. This sudden increase in yields above $250^{\circ} \mathrm{C}$ was also accompanied by a

275 significant decrease in the vanillin yields (shown in Figure 2(a) (ii)). The thermal degradation of

276 vanillin above $250^{\circ} \mathrm{C}$ can be attributed to the increased severity of alkaline wet oxidation

277 conditions. An increase in the alkali loading to $17.4 \mathrm{wt} \%$ showed a significant decrease in

278 vanillin yields as a function of temperature above $210^{\circ} \mathrm{C}$ and residence time of 15 mins, which

279 can again be attributed to the increased severity of the alkaline wet oxidation. Such thermal

280 degradation of vanillin during alkaline wet oxidation has been previously observed at

281 temperatures above $150^{\circ} \mathrm{C}$ (Araujo et al., 2010). Hence, reduced temperatures and higher

282 residence times (above $15 \mathrm{~min}$ ) would have sufficiently favored lignin conversion to vanillin in

283 the current study. However, in absence of alkaline conditions, vanillin yields from wet oxidation

284 of biorefinery lignin increased with an increase in temperature until $280^{\circ} \mathrm{C}$ but the yields, as

285 expected, were considerably lower than that obtained under alkaline conditions. The selectivity

286 toward oxidation of biorefinery lignin to vanillin can be considerably improved through the

287 optimizing temperature, residence time and the use of a catalyst (Fargues et al., 1996; Pinto et 
al., 2011; Wong et al., 2010). Since hardwood content in the forestry residue was lower, significant syringaldehyde yields were not expected using the current biorefinery lignin. Apart from vanillin, syringaldehyde and hydroxybenzaldehyde, other G-, S- and H-type lignin oxidation products was also found to be produced and was characterized through GC-MS analysis. Some of these products were identified as catechol (H), 4-ethyl guaiacol (G), 4-propyl guaiacol (G), homovanillyl alcohol (G), homovanillic acid (G), syringol (S) and propylveratrole (S). The GC-MS analysis also showed that the most predominant G-type lignin oxidation product was vanillin/iso-vanillin and S-type lignin oxidation product was syringaldehyde. Since it was difficult to obtain standards for some of the afore-mentioned compounds, the $\%$ peak area ratio was used to understand the effect of oxidation variables on the G-, S-, and H-type lignin components (Figure 3). Such comparisons have been done before (del Rio et al., 2007) and have been successfully used to compare the distribution of lignin components at different experimental conditions. It was found that no H-type lignin oxidation products were seen when alkali was added to wet oxidation of biorefinery lignin. However, it is evident from Figure 3 that predominantly G-type units were produced through wet oxidation of biorefinery lignin. Some Stype units were also produced at temperatures below $280^{\circ} \mathrm{C}$. Most of these compounds identified through GC-MS analysis are either intermediates or degradation products of vanillin, syringaldehyde and hydroxybenzaldehyde and the trends seen in Figure 3 is similar to that observed from liquid phase analysis shown in Figure 2.

\subsection{Effect of temperature, residence time and alkali loading on yield of acetic acid}

While there have been studies that have discussed the production of acetic acid primarily from the oxidation of cellulosic components (Jin et al., 2005), there has also been other studies that show the wet oxidation of lignin compounds resulting in acetic acid. Previous studies have 
311 shown that at high oxygen loadings (50-100\%), temperature of $300^{\circ} \mathrm{C}$ and 1 minute residence

312 time, maximum acetic acid yield of 9\% was obtained from lignin model compounds (Suzuki et

313 al., 2006). Other studies (Klinke et al., 2002) have indicated that at lower temperatures of 185 -

$314195^{\circ} \mathrm{C}$ and 6-12 bar $\mathrm{O}_{2}$ pressure, maximum acetic + formic acid yield of $14.2 \mathrm{wt} \%$ (or $142 \mathrm{mg} / \mathrm{g}$

315 dry biomass) was obtained from alkaline wet oxidation of wheat straw. In this study, a maximum

316 acetic acid yield of $107 \mathrm{mg} / \mathrm{g}$ dry biorefinery lignin was obtained at optimal conditions of 11.7

$317 \mathrm{wt} \%$ alkali loading, $280^{\circ} \mathrm{C}$ and residence time of 15 minutes at an $\mathrm{O}_{2}$ loading of $7.5 \%$. It can be

318 seen from Figure 2 (d) that the acetic acid yield increased with an increase in temperature up to

$319280^{\circ} \mathrm{C}$ with no statistical significance between yield obtained at 280 and $300^{\circ} \mathrm{C}$. However, when

320 alkali loading was increased to $17.4 \mathrm{wt} \%$, there was significant decrease in the acetic acid yield

321 above $280^{\circ} \mathrm{C}$, which could be a result of thermal degradation. At a residence time of 15 mins, the

322 acetic acid yields showed similar trends as lignin oxidation products. Previous study (Demesa et

323 al., 2015) have shown an increase in acetic acid yield from lignin at temperatures above $200^{\circ} \mathrm{C}$

324 until a residence time of around 20 min followed by saturation until a total residence time of 60

325 min. This study indicated that the decrease in carboxylic acid at high temperatures could be due

326 to condensation reactions between the lignin and carboxylic acids resulting in repolymerization

327 of the lignin components which, in turn, inhibits partial oxidation processes.

328 Previous studies (Jin et al., 2005; Fang et al., 2012; Wang et al., 2014) have indicated that acetic 329 acid can be produced from wet oxidation of glucose through 2 parallel pathways, one with lactic 330 acid as intermediate and the other with HMF and levulinic acid as intermediates. According to 331 these pathways, $1 \mathrm{~g}$ of glucose can theoretically produce $1 \mathrm{~g}$ lactic acid or $0.7 \mathrm{~g}$ HMF or $0.645 \mathrm{~g}$

332 levulinic acid eventually leading to $0.667 \mathrm{~g}$ acetic acid. The thermal degradation of $1 \mathrm{~g}$ of glucose 333 can also theoretically result in $1 \mathrm{~g}$ of formic acid. Hence, overall theoretical acetic acid yield from 
334 cellulosic components of biorefinery lignin can be estimated as $425 \mathrm{mg} / \mathrm{g}$ dry biorefinery lignin assuming complete oxidation of cellulose to acetic acid. However, due to the partial oxidation, as can be seen from Table 3, the concentrations of lactic acid, levulinic acid and HMF produced during wet oxidation was also taken into account and calculations predicted that, especially under alkaline conditions, greater amount of acetic acid was produced (at the optimal conditions) when compared to the maximum theoretical yield estimated from cellulose. For example, under optimized conditions (for acetic acid yield) of $11.7 \mathrm{wt} \%$ alkali, $280^{\circ} \mathrm{C}$ and $15 \mathrm{~min}$ residence time, approximately $243.23 \mathrm{mg}$ glucose/g dry biorefinery lignin (not taking into account the $\mathrm{C}_{5}$ sugars) was either left behind or reacted to produce formic acid, lactic acid, levulinic acid and HMF. This amounted to around $11.8 \mathrm{mg}$ glucose/g dry biorefinery lignin left behind that could have resulted in, theoretically, $7.85 \mathrm{mg}$ acetic acid/g dry biorefinery lignin. However, under these conditions, liquid phase analysis of the wet oxidized biorefinery lignin indicated almost $107 \mathrm{mg}$ acetic acid/g dry biorefinery lignin. The excess acetic acid would have to be produced from the wet oxidation of the lignin components since all the water-soluble extractives present in the biorefinery lignin was sufficiently removed during water washing before wet oxidation and the concentration of hemicellulosic components was found to be minimal in the biorefinery lignin. Incorporating the small amount of hemicellulosic components such as xylose in the calculations did not significantly alter the amount of acetic acid produced from the lignin components. Due to the significant differences in the chemical reactivity of the components present in biorefinery lignin, the theoretical calculations are only an approximate qualification to indicate that under the optimal conditions in this study, significant amounts of lignin oxidation products produced acetic acid at higher temperatures $\left(>250^{\circ} \mathrm{C}\right)$. However, these theoretical calculations also showed that the cellulosic components present in the biorefinery lignin were the primary sources for acetic 
357 acid production when compared to lignin components. Since acetic acid has significant

358 applications in chemical and fuel sectors, an increased acetic acid yield from the biorefinery

359 lignin (from both sugar and lignin components) is more desirable when compared to a pure

360 lignin stream. Based on the data obtained from this study, the overall process reaction scheme for

361 production of bioproducts from alkaline wet oxidation of biorefinery lignin is shown in Figure 4.

\subsection{Comparison between FTIR spectra of residual solids after wet oxidation of biorefinery lignin}

363 The residual solids left behind after alkaline wet oxidation of biorefinery lignin was used to 364 determine the extent of deconstruction of cellulosic and lignin linkages. The variation of FTIR

365 absorbance over the entire spectrum as a function of temperature, residence time and alkali 366 loading is shown in Figure 5 (The assignment of FTIR bands can be found in Table S1 in the 367 supplementary section). It can be seen from Figure 5(a) that in absence of alkali, there was no 368 significant effect of temperature on the cellulosic and lignin based structures in the residual 369 solids after wet oxidation when residence time was 5 mins. However, there was a significant 370 reduction in $-\mathrm{OH}$ based cellulosic linkages $\left(>3300 \mathrm{~cm}^{-1}\right)$ and an increase in the primary and 371 secondary alcoholic linkages $\left(900-1200 \mathrm{~cm}^{-1}\right)$ with an increase in temperature, when residence

372 time was 15 mins. This could be attributed to the primary oxidation of cellulosic moieties present

373 in biorefinery lignin and can be attributed to the low severity of the wet oxidation treatment (due 374 to absence of alkali) since a complete oxidation was not seen. This observation can be further 375 corroborated by a negligible change in the aromatic structural vibrations $\left(1200-1500 \mathrm{~cm}^{-1}\right)$ 376 attributed to lignin components. The variation in FTIR absorbance as a function of residence 377 time and temperature was significantly lower during non-alkaline wet oxidation when compared 378 to $11.7 \mathrm{wt} \%$ alkali, $15 \mathrm{~min}$ residence time (Figure 5(b)) and $17.4 \mathrm{wt} \%$ alkali, 5 and $15 \mathrm{~min}$ 379 residence time (Figure 5(c)). 
Increasing alkali loading to $11.7 \mathrm{wt} \%$ alkali while maintaining residence time of 5 mins did not show any significant effect of temperature on linkages present in biorefinery lignin. Partial oxidation of biomass has been previously shown to occur at low residence times and insufficiently high temperatures resulting in formation of low molecular weight organic products from polymeric substrates (Bhargava et al., 2006). However, when residence time was increased to 15 mins, there was initially a decrease in the $-\mathrm{OH}$ based cellulosic linkages with increase in temperature until around $250^{\circ} \mathrm{C}$ followed by a significant increase at $300^{\circ} \mathrm{C}$. The aromatic skeletal vibrations related to the lignin components increased with an increase in temperature to $300^{\circ} \mathrm{C}$. It can also be seen that the sudden increase in the $-\mathrm{OH}$ based cellulosic linkages at $300^{\circ} \mathrm{C}$ was accompanied by a significant reduction in the alcoholic groups. A possible reason for this trend could be a secondary oxidation reaction for cellulosic components which has been previously shown (Jin et al., 2005; Jin et al., 2006; Zhou et al., 2006) for increased carboxylic acid production such as lactic acid (shown in Table 2).

Similar trends were seen when the alkali loading was increased to $17.4 \mathrm{wt} \%$ (Figure 5(c)). It can be seen from both the liquid phase data as well as FTIR analysis on the residual solids that $5 \mathrm{~min}$ residence time was insufficient for complete oxidation of biorefinery lignin resulting in poor yields for biochemicals tested as part of the study. While alkaline wet oxidation at higher temperatures $\left(>180^{\circ} \mathrm{C}\right)$ and residence time of 15 mins resulted in increased sugar oxidation or degradation, the consistent increase in the aromatic skeletal vibrations in the residual solids that usually attribute to the lignin structures, could indicate that further oxidation to increase yield of lignin oxidation products such as vanillin, syringaldehyde and hydroxybenzaldehyde could be achieved with a further increase in residence time. An increase in temperature would, however, 
402 result in thermal degradation of these lignin oxidation products resulting in organic acids such as

403 formic and acetic acid as can be seen in this study.

\section{Conclusions}

405 The current study examined the applicability of biorefinery lignin from forestry residues to 406 produce high value products. Alkaline wet oxidation at higher temperatures was found to favor

407 formation of oxidation products such as lactic, acetic and formic acids and partial oxidation of 408 lignin to vanillin. This was confirmed through FTIR analysis on residual solids that showed an 409 increase in the aromatic skeletal vibrations as function of residence time between 180 and $250^{\circ} \mathrm{C}$.

410 Due to the low feedstock cost, further process optimization (primarily residence time) to

411 efficiently convert biorefinery lignin stream to bio-based chemicals could potentially create more 412 value into future biorefineries.

\section{Acknowledgements}

414 The authors would like to acknowledge the financial and feedstock support through the

415 Agricultural and Food Research Initiative (AFRI) competitive grant (No. 2011-68005-30416)

416 obtained from USDA National Institute of Food and Agriculture (NIFA) as part of the Northwest

417 Advanced Renewables Alliance (NARA). The authors would also like to thank the financial

418 support from Coordenação de Aperfeiçoamento de Pessoal de Nível Superior (CAPES) and

419 Conselho Nacional de Desenvolvimento Cientifico e Tecnológico (CNPq), Brazil. The authors

420 would also like to thank Ms. Barbara Pereira, Engineering School of Lorena, Brazil for running

421 FTIR analysis on the biorefinery lignin and residual solids, Mr. Justin Fry and Mr. Marty

422 Kroeger at Washington State University, Tri-cities for technical support on biorefinery lignin 423 feed. 


\section{References}

425 1. Araujo, J.D.P., Grande, C.A., Rodrigues, E.A., 2010. Vanillin production from lignin

426 oxidation in a batch reactor. Chem. Eng. Res. Design, 88, 1024-1032.

427 2. Bhargava, S.K., Tardio, J., Prasad, J., Foger, K., Akolekar, D.B., Grocott, S.C., 2006. Wet 428 oxidation and catalytic wet oxidation. Ind. Eng. Chem. Res., 45, 1221-1258.

429 3. Biswas, R., Teller, P.J. and Ahring, B.K., 2015. Pretreatment of forest residues of Douglas fir 430 by wet explosion for enhanced enzymatic saccharification. Bioresour. Technol., 192, 46-53.

431 4. Biswas, R., Uellendahl, H., Ahring, B.K., 2015. Wet explosion: a universal and efficient pretreatment process for lignocellulosic biorefineries. BioEnergy Res., http://dx.doi.org/10.1007/s12155-015-9590-5.

5. Capanema, E.A., Balakshin, M.Y., Kadla, J.F., 2005. Quantitative characterization of a hardwood milled wood lignin by nuclear magnetic resonance spectroscopy. J. Agric. Food Chem., 52, 1850-1860.

6. Cheng, J., Leu, S-Y., Zhu, J.Y., Gleisner, R., 2015. High titer and yield ethanol production from undetoxified whole slurry of Douglas-fir forest residue using $\mathrm{pH}$ profiling in SPORL. Biotechnol. Biofuels, 8, 22, doi: 10.1186/s13068-015-0205-3.

7. David, C., Atarhouch, T., 1987. Utilizxation of waste cellulose. VIII. Enzymatic hydrolysis of spruce bark by cellulases of Trichoderma viride. Appl. Biochem. Biotechnol., 16, 51-59.

442 8. del Rio, R.C., Gutierrez, A., Rordriguez, I.M., Ibarra, D., Martinez, A.T. 2007. Identification 443 of residual lignin markers in eucalypt kraft pulps by Py-GC/MS. J. Anal. Appl. Pyrolysis, 79, 444 $39-46$. lignin for the production of carboxylic acids. Chem. Eng. Technol., 38, 2270-2278. 
10. Lin, S.Y., Dence, C.W., 1992. Methods in Lignin Chemistry, Springer-Verlag, Berlin, New York.

11. Fache, M., Boutevin, B., Caillol, S., 2016. Production from lignin and its use as a renewable 450 chemical. ACS Sus. Chem. Eng., 4, 35-46.

451 12. Faix, O., Argyropoulos, D.S., Robert, D. and Neirinck, V., 1994. Determination of hydroxyl 452 groups in lignin evaluation of ${ }^{13} \mathrm{C}-,{ }^{13} \mathrm{P}-\mathrm{NMR}$, FTIR and wet chemical methods.

$453 \quad$ Holzforschung, 48, 387-394.

454 13. Fang, Y., Zeng, X., Yan, P., Jing, Z. and Jin, F., 2012. An acidic two-step hydrothermal 455 process to enhance acetic acid production from carbohydrate biomass. Ind. Eng. Chem. Res., 456 $43,2343-2352$.

457

458

459

460

14. Fargues, C., Mathias, A., Rodrigues, A., 1996. Kinetics of vanillin production from kraft lignin oxidation. Ind. Eng. Chem. Res., 35, 28-36.

15. Guay, D.F., Cole, B.J.W., Fort, R.C., Hausman, M.C., Genco, J.M., Elder, T.J., Overly, K.R., 2001. Mechanisms of oxidative degradation of carbohydrates during oxygen delignification. II. Reaction of photochemically generated hydroxyl radicals with methyl- $\beta$-cellulose. J. Wood Chem. Technol., 21, 67-79.

16. Himmel, M.E., Ding, S-Y., Johnson, D.K., Adney, W.S., Nimlos, M.R., Brady, J.W. and Foust, T.D., 2007. Biomass recalcitrance: engineering plants and enzymes for biofuels production. Science, 315, 804-807.

17. Jin, F., Zhou, Z., Moriya, T., Kishida, H., Higashijima, H., Enomoto, H., 2005. Controlling hydrothermal reaction pathways to improve acetic acid production from carbohydrate biomass. Environ. Sci. Technol., 39, 1893-1902. 
18. Jin, F., Zhou, Z., Kishita, A., Enomoto, H., Moriya, T., 2006. Hydrothermal conversion of biomass to acetic acid. J. Mater. Sci., 41, 1495-1500.

19. Jurgensen, M.F., Harvey, A.E., Graham, R.T., Page-Dumroese, D.S., Tonn, J.R., Larsen, M.J., Jain, T.B., 1997. Impacts of timber harvesting on soil organic matter, nitrogen, productivity, and health of inland North-west forests. Forest Sci., 42, 234-251.

20. Ke, J., Laskar, D.D., Singh, D., Chen, S., 2011. In situ lignocellulosic unlocking mechanism for carbohydrate hydrolysis in termites: crucial lignin modification. Biotechnol. Biofuels, 4, 17, doi: 10.1186/1754-6834-4-17.

21. Klinke, H.B., Ahring, B.K., Schmidt, A.S., Thomsen, A.B., 2002. Characterization of degradation products from alkaline wet oxidation of wheat straw. Bioresour. Technol., 82, $15-26$.

22. Kubo, S. and Kadla, J.F., 2005. Hydrogen bonding in lignin: a fourier transform infrared model compound study. Biomacromolecules, 6, 2815-2821.

23. Mathias, A.L., Rodrigues, A.E., 1995. Production of vanillin by oxidation of pine kraft lignin with oxygen. Holzforshung, 49, 273-278.

24. Pandey, K.K., 1999. A study of chemical structure of soft and hardwood and wood polymers by FTIR spectroscopy. J. Appl. Polym. Sci., 71, 1969-1975.

25. Pinto, P.C.R., de Silva, E.A.B., Rodrigues, A.E., 2011. Insights into oxidative conversion of lignin to high-added-value phenolic aldehydes. Ind. Eng. Chem. Res., 50, 741-748.

26. Rana, D., Rana, V., Ahring, B.K., 2012. Producing high sugar concentrations from loblolly pine using wet explosion pretreatment. Bioresour. Technol., 121, 61-67. 
27. Rana, D., Laskar, D.D., Srinivas, K., Ahring, B.K., 2015. Wet explosion pretreatment of loblolly pine leads to an increase in methoxylation of the lignin. Bioresour. Bioproc., 2, 26, doi: 10.1186/s40643-015-0054-8.

28. Rocha, G.J.M., Martin, C., da Silva, V.F.N., Gomez, E.O., Goncalves, A.R., 2012. Mass balance of pilot-scale treatment of sugarcane bagasse by steam explosion followed by alkaline delignification. Bioresour. Technol., 111, 447-452.

29. Rummer, B., Prestemom, J., May, D., Miles, P., Vissage, J., McRoberts, R., Liknes, G., Shepperd, W.D., Ferguson, D., Elliot, W., Miller, S., Reutebuch, S., Barbour, R.J., Fired, J., Stokes, B., Bilek, E. and Skog, K., 2005, http://www.treesearch.fs.fed.us/pubs/8478 (Accessed March 6, 2015)

30. Sim, S.F., Mohamed, M., Lu, N.A.L.M.I., Sarman, N.S.P., Samsudin, S.N.S., 2012. Computer-assisted analysis of fourier transform infrared (FTIR) spectra for characterization of various treated and untreated agriculture biomass. BioResources, 2012, 7, 5367-5380.

31. Sluiter, A., Hames, B., Ruiz, R., Scarlata, C., Sluiter, J., Templeton, D., Crocker, D., 2011. Determination of structural carbohydrates and lignin in biomass. NREL/TP-510-42618 http://www.nrel.gov/biomass/analytical procedures.html (Accessed February 4, 2015).

32. Stephen, J.D., Mabee, W.E., Saddler, J.N., 2010. Biomass logistics as a determinant of second-generation biofuel facility scale, location and technology selection. Biofpr., 4, 503518.

33. Suzuki, H., Cao, J., Jin, F., Kishita, A., Enomoto, H., 2006. Wet oxidation of lignin model compounds and acetic acid production. J. Mater. Sci., 41, 1591-1597.

34. Perlack, R.D., Stokes, B.J., 2011, U.S. billion-ton update: biomass supply for a bioenergy and bioproducts industry, U.S. Department of Energy Report ORNL/TM-2011/224, 
https://www1.eere.energy.gov/bioenergy/pdfs/billion_ton_update.pdf (Accessed August 2011)

35. Wang, Y., Yan, G., Jin, F., 2014. Hydrothermal conversion of cellulose into organic acids with a $\mathrm{CuO}$ oxidant, in: Jin, F. (Ed.) Application of Hydrothermal Reactions in Biomass Conversion, Springer-Verlag, Berline, Heidelberg, 31-59.

36. Wong, Z., Chen, K., Li, J., 2010. Formation of vanillin and syringaldehyde in an oxygen delignification process. Bioresources, 6, 1509-1516.

37. Zhou, Z., Jin, F., Enomoto, H., Moriya, T., Higashigima, H., 2006. A continuous flow reaction system for producing acetic acid by wet oxidation of biomass waste. J. Mater. Sci.,

\section{Figure Caption List}

528 Figure 1. Variation in concentration ( $\mathrm{mg} / \mathrm{g}$ dry biomass) of sugars and sugar oxidation products 529 including (a) glucose, (b) formic acid, (c) lactic acid as a function of temperature at different $530 \mathrm{NaOH}$ loadings and residence time of (i) 5 mins and (ii) 15 mins. $(\bullet-0 \mathrm{wt} \% \mathrm{NaOH} ; \boldsymbol{\Delta}-$ 531 $11.7 \mathrm{wt} \% \mathrm{NaOH} ;-17.4 \mathrm{wt} \% \mathrm{NaOH})$

532 Figure 2. Variation in concentration ( $\mathrm{mg} / \mathrm{g}$ dry biomass) of lignin oxidation products (a) vanillin,

533 (b) hydroxybenzaldehyde, (c) syringaldehyde, and (d) acetic acid as a function of temperature at 534 different $\mathrm{NaOH}$ loadings and residence time of (i) 5 mins and (ii) 15 mins. (• $-0 \mathrm{wt} \% \mathrm{NaOH}$; $535-11.7 \mathrm{wt} \% \mathrm{NaOH} ; \mathbf{\square}-17.4 \mathrm{wt} \% \mathrm{NaOH})$ 
536 Figure 3. Variation in \% lignin oxidation products in form of H-, S- and G-type compounds

537 obtained at 10\% solids and (A) $0 \% \mathrm{NaOH}$ loading; (B) $11.7 \% \mathrm{NaOH}$ loading; (C) $17.4 \% \mathrm{NaOH}$

538 loading as a function of temperature at different reaction times (i) 5 min; and (ii) 15 mins.

539 Figure 4. Overall process reaction scheme showing the alkaline wet oxidation of biorefinery

540 lignin to bioproducts.

541 Figure 5. Variation in FTIR absorbance of residual solids obtained at 10\% solids loading and (a)

$5420 \% \mathrm{NaOH}$ loading; (b) $11.7 \% \mathrm{NaOH}$ loading; (c) $17.4 \% \mathrm{NaOH}$ loading as a function of

543 wavelength at different temperatures and reaction times of (i) $5 \mathrm{~min}$; and (ii) $15 \mathrm{mins}$

544 Table Caption List

545 Table 1: Compositional analysis of biorefinery (FS-10) lignin

546 Table 2: Bioproducts obtained from wet oxidation of biorefinery lignin (FS-10) as a function of 547 alkali loading, time and temperature 

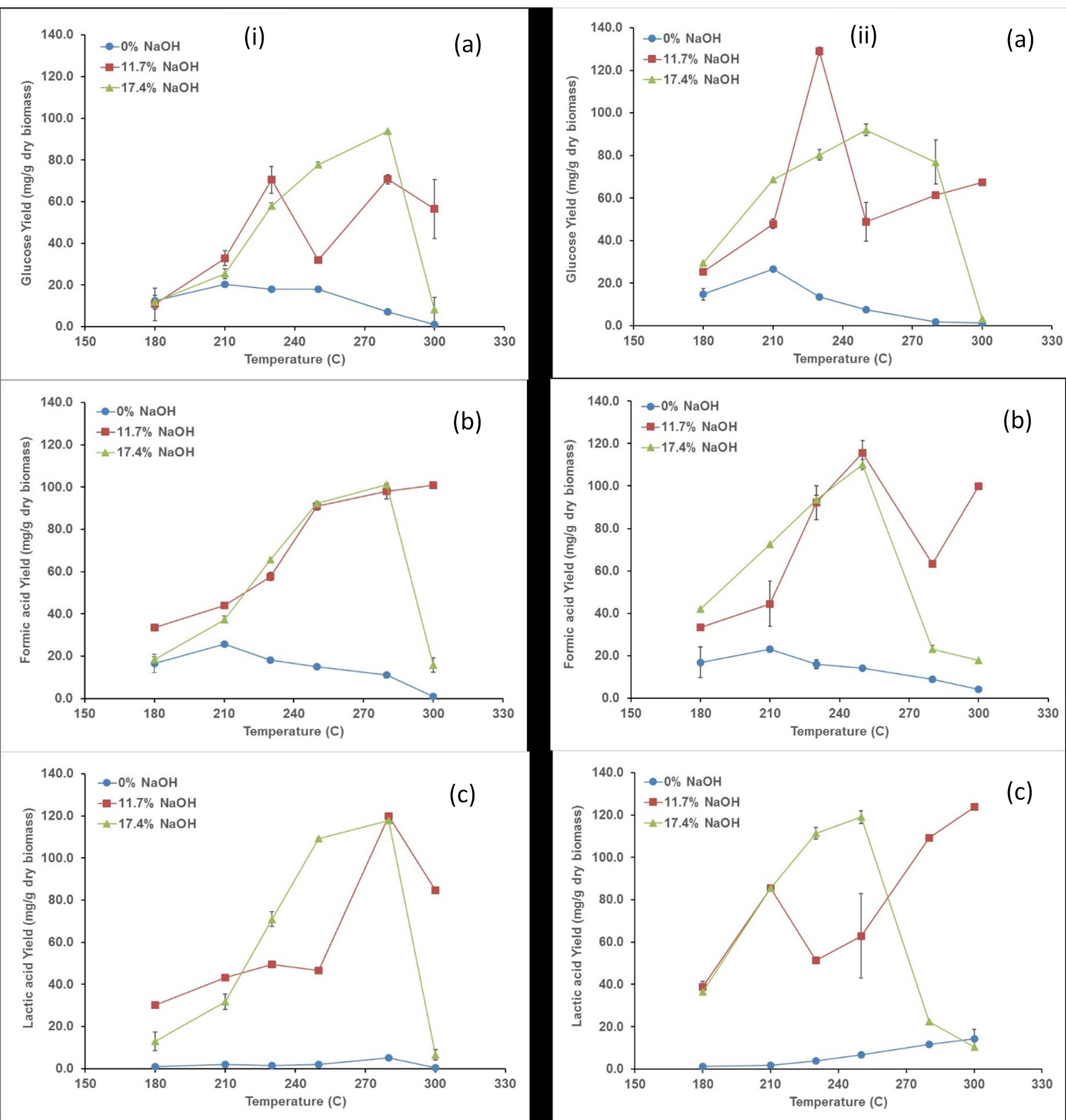

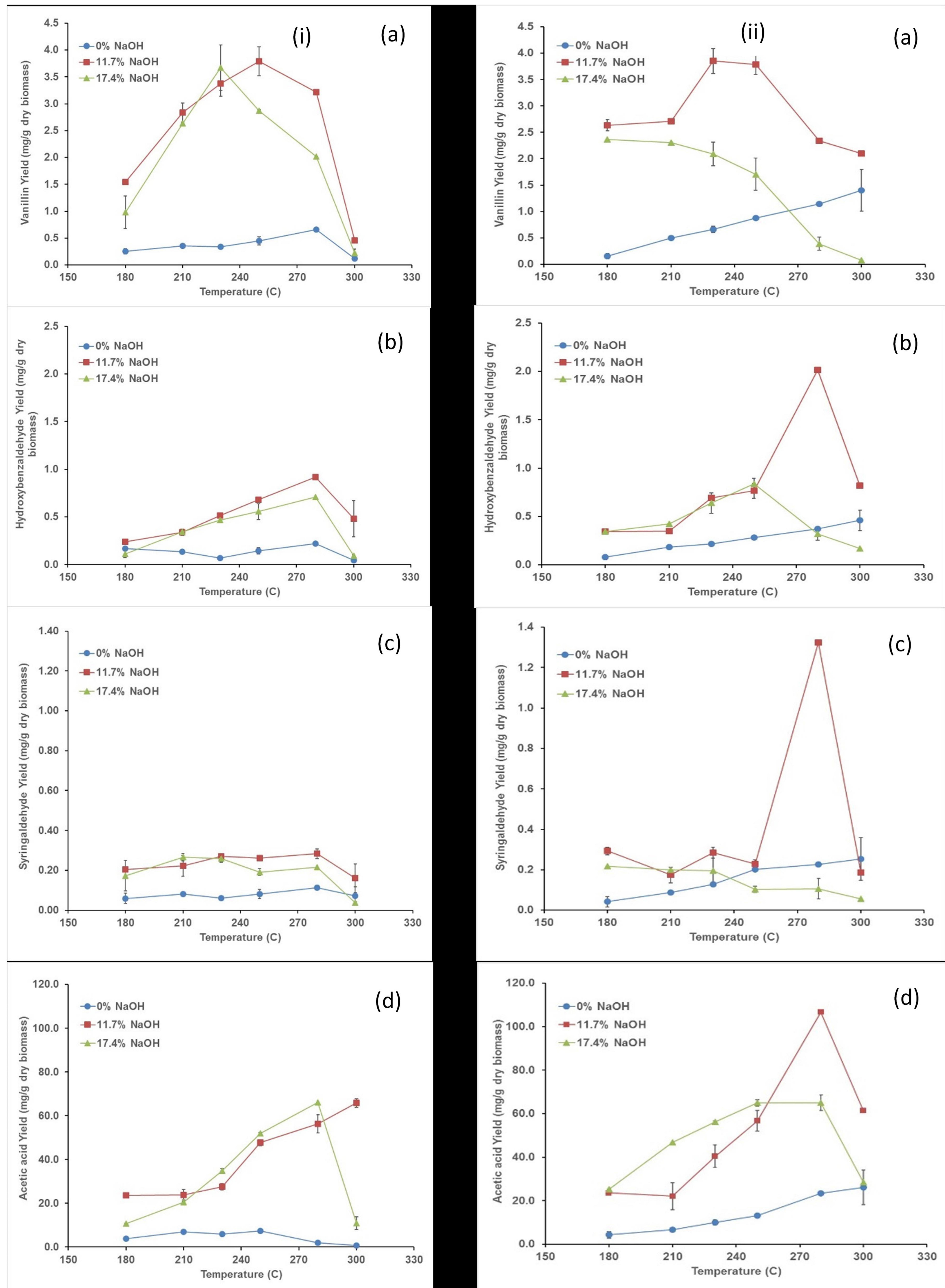
Figure 3

A (i)

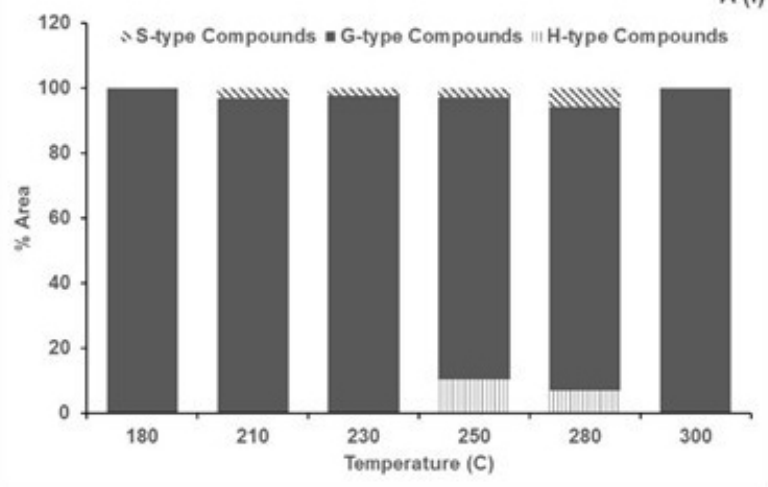

B (i)

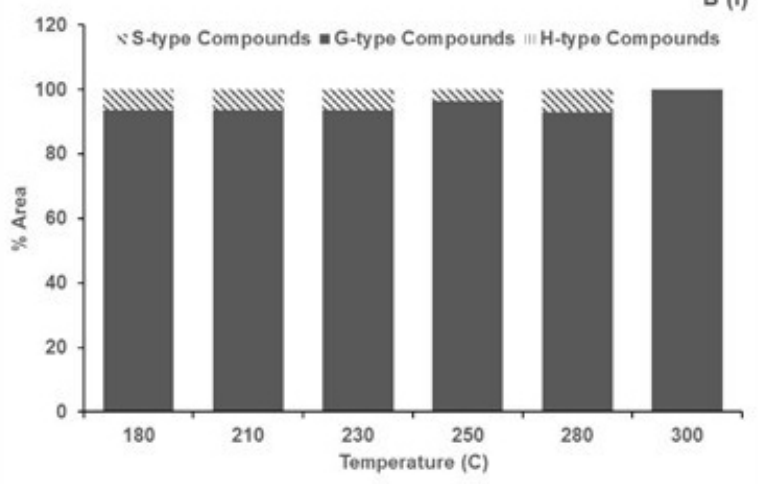

C (i)

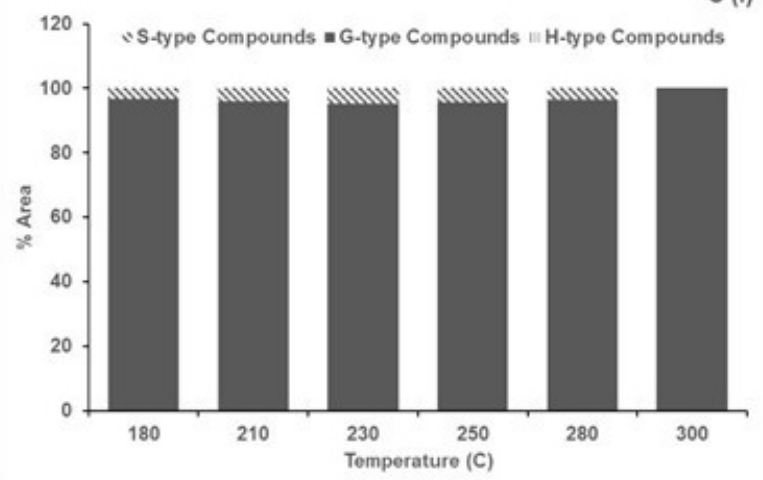

A (ii)

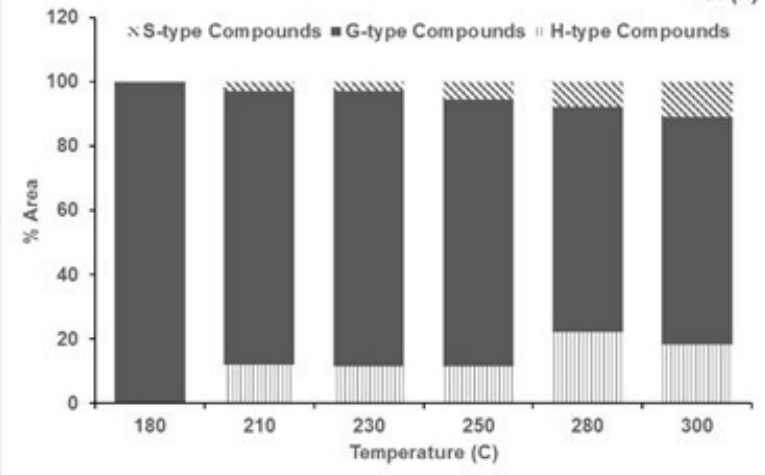

B (ii)

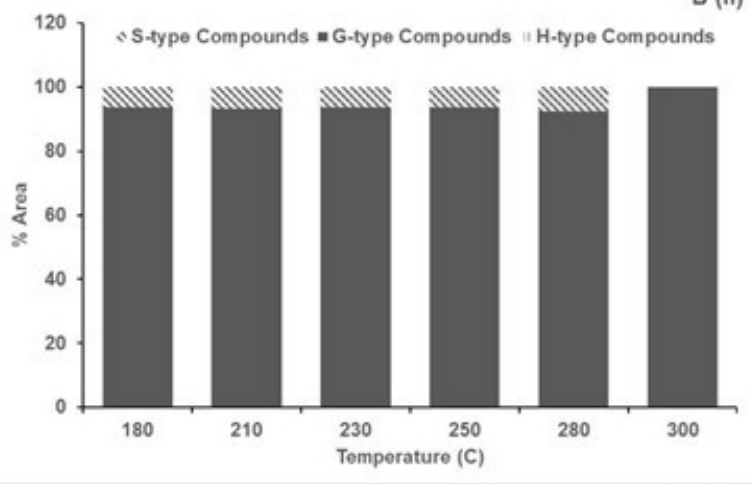

C (ii)

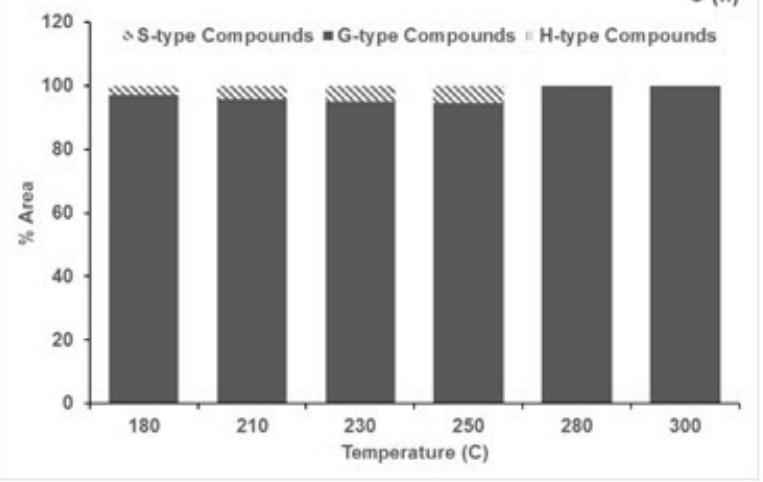



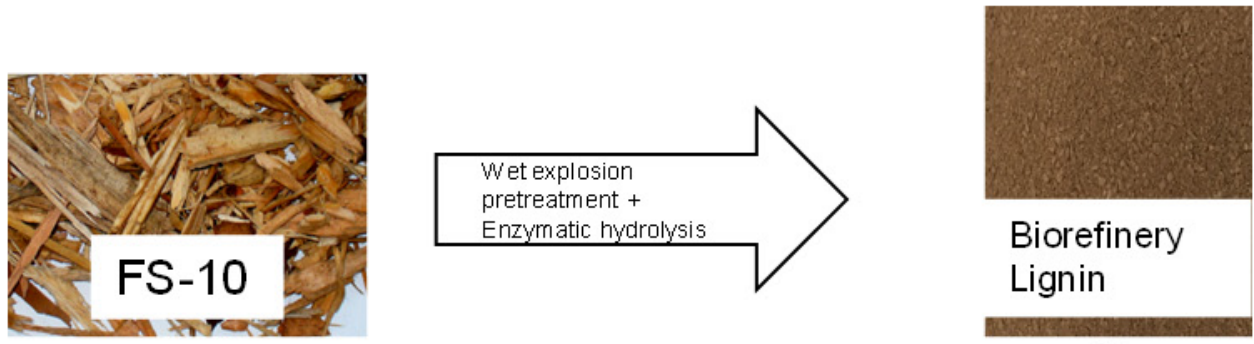

Biorefinery

Lignin

\%

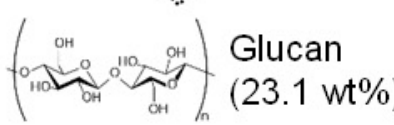

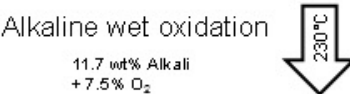

Glucose

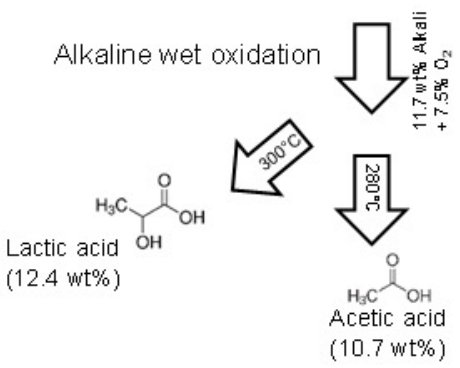

圈 Thermal treatment

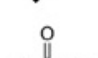

$\mathrm{H}^{\mathrm{OH}}$

Formic acio

(11. $6 \mathrm{wt} \%)$

(10.7wt\%)

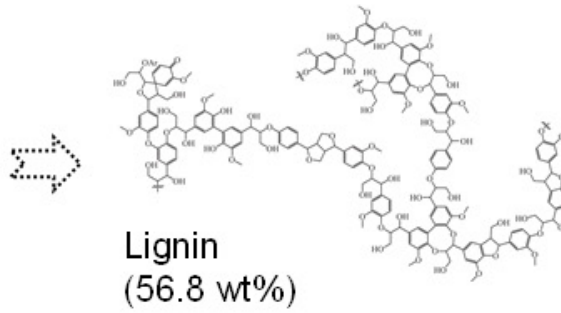

(56.8 wt\%)
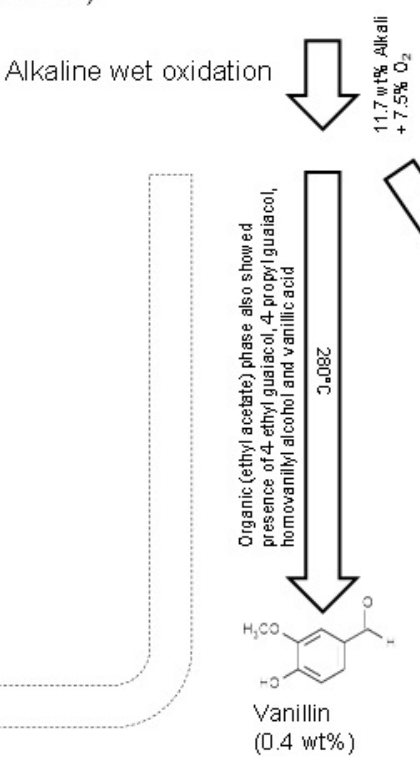
Figure 5
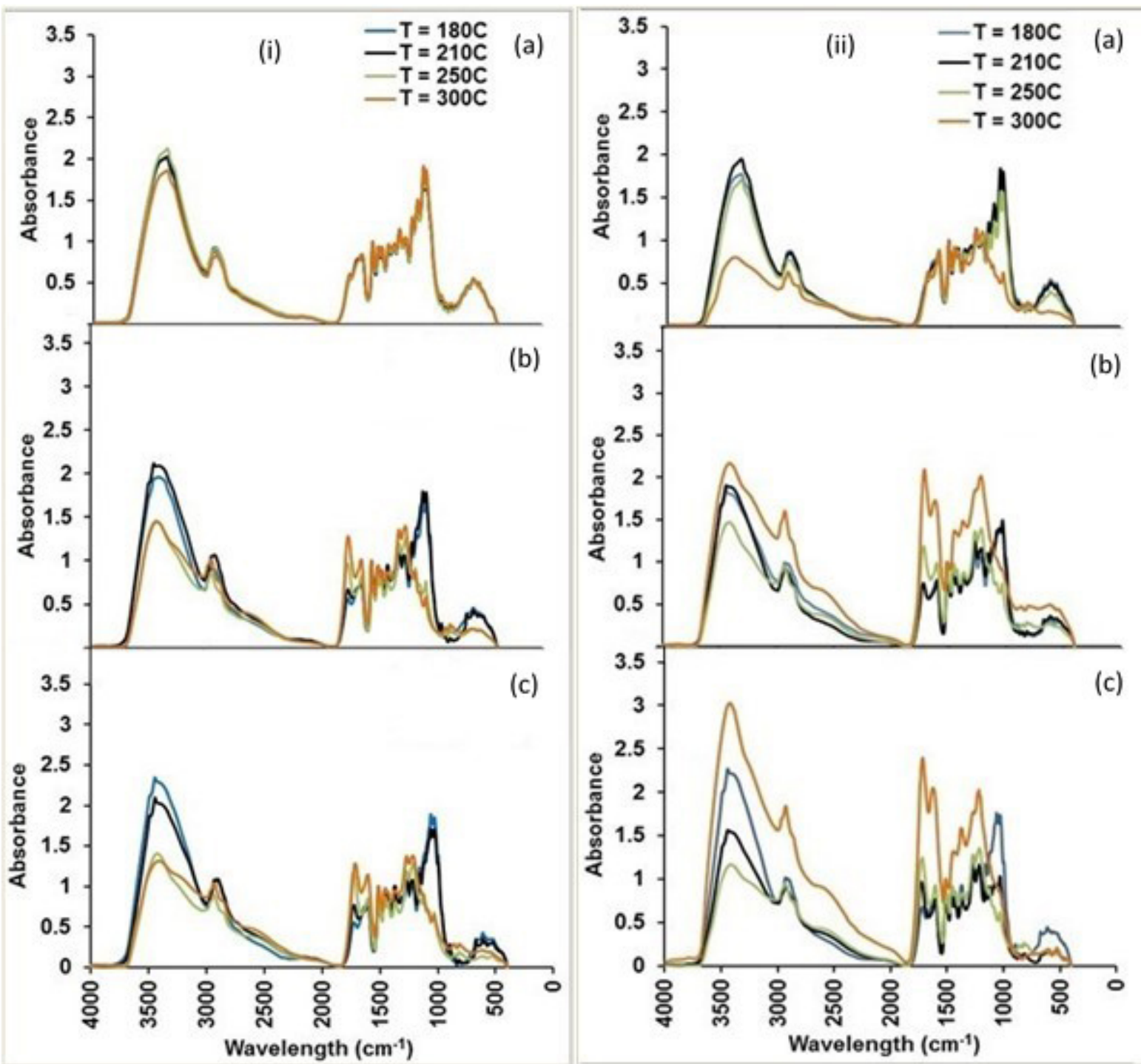
Table 1: Compositional analysis of biorefinery (FS-10) lignin

\begin{tabular}{|c|c|c|}
\hline Component & $\begin{array}{c}\text { Composition of } \\
\text { FS-10(\%) }\end{array}$ & $\begin{array}{c}\text { Composition of Wet- } \\
\text { Exploded FS-10 (\%) }\end{array}$ \\
\hline Cellulose & 30.3 & 23.1 \\
\hline Xylan & 5.40 & 0.19 \\
\hline Galactan & 2.20 & 0.00 \\
\hline Arabinan & 1.40 & 2.21 \\
\hline Mannan & 8.80 & 0.30 \\
\hline Ash & 0.70 & 56.8 \\
\hline Lignin & 46.2 & 11.8 \\
\hline Extractives & 2.80 & 0.84 \\
\hline
\end{tabular}


Table 2: Bioproducts obtained from wet oxidation of biorefinery lignin (FS-10) as a function of alkali loading, time and temperature

\begin{tabular}{|c|c|c|c|c|c|c|c|c|c|c|c|c|c|c|}
\hline $\begin{array}{l}\mathrm{NaOH} \\
\text { Concentr } \\
\text { ation }(\mathrm{g} / \mathrm{g} \\
\text { biomass) }\end{array}$ & $\begin{array}{l}\% \\
\text { Solids }\end{array}$ & $\begin{array}{l}\text { Time } \\
(\mathrm{min})\end{array}$ & $\begin{array}{l}\text { Tempe } \\
\text { rature } \\
\left({ }^{\circ} \mathrm{C}\right)\end{array}$ & Glucose & Xylose & $\mathrm{FA}^{\mathrm{a}}$ & $\mathrm{AA}^{\mathrm{b}}$ & $\mathrm{LA}^{\mathrm{c}}$ & $\mathrm{LeA}^{\mathrm{d}}$ & Furfural & $\mathrm{HMF}^{\mathrm{e}}$ & $\mathrm{HBA}^{\mathrm{f}}$ & Vanillin & $\mathrm{SA}^{\mathrm{g}}$ \\
\hline \multirow{12}{*}{$\begin{array}{c}0.0 \\
(0 \% \\
\text { Loading) }\end{array}$} & \multirow[t]{12}{*}{9.95} & \multirow[t]{6}{*}{5} & 180 & 12.5 & 4.50 & 16.7 & 3.82 & 0.971 & 0.495 & 0.733 & 1.64 & 0.168 & 0.254 & 0.0591 \\
\hline & & & 210 & 20.4 & 10.7 & 25.8 & 6.88 & 2.07 & 1.20 & 0.750 & 0.538 & 0.134 & 0.353 & 0.0802 \\
\hline & & & 230 & 18.0 & 14.9 & 18.3 & 5.96 & 1.39 & 0.718 & 3.64 & 0.957 & 0.0697 & 0.339 & 0.0606 \\
\hline & & & 250 & 17.9 & 10.5 & 15.1 & 7.41 & 1.93 & 1.09 & 8.73 & 3.30 & 0.144 & 0.446 & 0.0811 \\
\hline & & & 280 & 7.05 & 3.53 & 11.2 & 1.94 & 5.11 & 1.09 & 9.92 & 1.82 & 0.222 & 0.661 & 0.114 \\
\hline & & & 300 & 1.15 & 0.404 & 0.956 & 0.711 & 0.410 & 0.132 & 1.11 & 0.0921 & 0.0466 & 0.116 & 0.0721 \\
\hline & & \multirow[t]{6}{*}{15} & 180 & 14.8 & 7.90 & 16.9 & 4.29 & 1.33 & 0.601 & 1.21 & 1.69 & 0.0778 & 0.150 & 0.0423 \\
\hline & & & 210 & 26.7 & 13.3 & 23.2 & 6.74 & 1.89 & 0.690 & 5.28 & 1.95 & 0.182 & 0.502 & 0.0878 \\
\hline & & & 230 & 13.5 & 6.86 & 16.1 & 10.0 & 3.96 & 1.09 & 11.6 & 3.47 & 0.214 & 0.660 & 0.129 \\
\hline & & & 250 & 7.68 & 3.62 & 14.1 & 13.1 & 6.81 & 2.08 & 20.7 & 5.75 & 0.282 & 0.872 & 0.203 \\
\hline & & & 280 & 1.73 & 1.04 & 8.81 & 23.5 & 11.8 & 2.25 & 11.2 & 4.54 & 0.370 & 1.142 & 0.227 \\
\hline & & & 300 & 1.25 & 1.22 & 4.10 & 26.2 & 14.3 & 3.12 & 2.74 & 0.723 & 0.459 & 1.402 & 0.254 \\
\hline \multirow{12}{*}{$\begin{array}{c}1.0 \\
(11.7 \% \\
\text { Loading) }\end{array}$} & \multirow[t]{12}{*}{10.0} & \multirow[t]{6}{*}{5} & 180 & 10.75 & 5.86 & 33.5 & 23.6 & 30.3 & 3.40 & 0.00 & 0.00 & 0.240 & 1.54 & 0.204 \\
\hline & & & 210 & 32.9 & 6.73 & 44.0 & 23.9 & 43.2 & 2.64 & 0.00 & 0.00 & 0.339 & 2.84 & 0.223 \\
\hline & & & 230 & 70.4 & 9.81 & 57.7 & 27.6 & 49.6 & 2.36 & 1.14 & 3.05 & 0.515 & 3.38 & 0.270 \\
\hline & & & 250 & 32.0 & 6.09 & 90.9 & 47.7 & 46.7 & 4.26 & 4.11 & 3.83 & 0.681 & 3.79 & 0.262 \\
\hline & & & 280 & 70.7 & 11.3 & 98.0 & 56.4 & 120 & 5.21 & 2.40 & 0.00 & 0.919 & 3.22 & 0.283 \\
\hline & & & 300 & 56.5 & 6.06 & 101.0 & 65.8 & 84.6 & 5.34 & 3.54 & 0.00 & 0.482 & 0.459 & 0.161 \\
\hline & & \multirow[t]{6}{*}{15} & 180 & 25.3 & 6.20 & 33.3 & 23.6 & 38.9 & 3.28 & 0.00 & 0.00 & 0.345 & 2.63 & 0.293 \\
\hline & & & 210 & 47.8 & 8.65 & 44.5 & 22.1 & 85.4 & 2.01 & 0.00 & 0.00 & 0.346 & 2.71 & 0.175 \\
\hline & & & 230 & 129 & 10.29 & 92.1 & 40.4 & 51.4 & 3.97 & 2.55 & 3.43 & 0.693 & 3.85 & 0.285 \\
\hline & & & 250 & 48.9 & 8.36 & 116 & 56.7 & 62.8 & 6.49 & 1.95 & 2.07 & 0.767 & 3.79 & 0.228 \\
\hline & & & 280 & 61.4 & 9.34 & 63.4 & 107 & 109 & 5.83 & 3.22 & 0.00 & 2.01 & 2.34 & 1.32 \\
\hline & & & 300 & 67.4 & 4.52 & 100.0 & 61.2 & 124 & 5.49 & 5.85 & 0.00 & 0.819 & 2.10 & 0.185 \\
\hline \multirow{3}{*}{$\begin{array}{c}1.5 \\
(17.4 \% \\
\text { Loading) }\end{array}$} & \multirow[t]{3}{*}{10.0} & \multirow[t]{3}{*}{5} & 180 & 11.9 & 5.64 & 18.4 & 10.67 & 12.9 & 2.02 & 0.00 & 0.00 & 0.111 & 0.981 & 0.174 \\
\hline & & & 210 & 25.4 & 6.07 & 37.3 & 20.5 & 31.8 & 2.66 & 0.00 & 0.00 & 0.343 & 2.63 & 0.266 \\
\hline & & & 230 & 57.9 & 10.9 & 65.6 & 34.9 & 71.0 & 3.03 & 4.51 & 0.00 & 0.466 & 3.67 & 0.259 \\
\hline
\end{tabular}




\begin{tabular}{|c|c|c|c|c|c|c|c|c|c|c|c|c|c|c|}
\hline & & & 250 & 77.6 & 12.3 & 92.2 & 51.9 & 109 & 3.67 & 3.29 & 0.457 & 0.557 & 2.87 & 0.191 \\
\hline & & & 280 & 93.8 & 25.3 & 101.0 & 66.2 & 118 & 5.81 & 8.07 & 3.10 & 0.708 & 2.01 & 0.216 \\
\hline & & & 300 & 8.16 & 3.12 & 15.9 & 10.9 & 6.59 & 1.45 & 0.00 & 0.00 & 0.094 & 0.218 & 0.0378 \\
\hline & & 15 & 180 & 29.4 & 7.16 & 41.9 & 25.4 & 36.5 & 3.79 & 0.00 & 0.00 & 0.341 & 2.37 & 0.218 \\
\hline & & & 210 & 68.7 & 13.0 & 72.4 & 46.8 & 85.4 & 5.18 & 0.00 & 0.00 & 0.425 & 2.31 & 0.200 \\
\hline & & & 230 & 80.3 & 11.9 & 93.7 & 56.2 & 111 & 5.79 & 0.998 & 0.387 & 0.639 & 2.09 & 0.194 \\
\hline & & & 250 & 92.0 & 12.4 & 110 & 65.0 & 119 & 4.87 & 3.47 & 3.56 & 0.836 & 1.71 & 0.1035 \\
\hline & & & 280 & 76.9 & 8.22 & 23.2 & 65.0 & 22.4 & 6.12 & 3.50 & 1.64 & 0.320 & 0.388 & 0.1068 \\
\hline & & & 300 & 3.11 & 3.13 & 17.8 & 28.3 & 10.4 & 1.48 & 0.00 & 0.00 & 0.171 & 0.0760 & 0.0570 \\
\hline
\end{tabular}

All concentrations are in mg/g dry biomass; ${ }^{\mathrm{a} F A-F o r m i c ~ a c i d ; ~}{ }^{\mathrm{b} A A-A c e t i c ~ a c i d ; ~}{ }^{\mathrm{c}}$ LA-Lactic acid; ${ }^{\mathrm{d}}$ LeA-Levulinic acid; ${ }^{\mathrm{e}} \mathrm{HMF}-5$-Hydroxymethyl furfural; ${ }^{\mathrm{f}} \mathrm{HBA}$ Hydroxybenzaldehyde; ' ${ }^{\mathrm{S}} \mathrm{A}$-Syringaldehyde 